\title{
IMPLEMENTASI GERAKAN LITERASI SEKOLAH DI SEKOLAH MENENGAH ATAS SEBAGAI SEKOLAH SASARAN PELAKSANA KURIKULUM 2013 SE-KABUPATEN JAYAPURA
}

\author{
THE IMPLEMENTATION OF SCHOOL LITERACY MOVEMENT AT \\ SENIOR HIGH SCHOOLS AS SCHOOL TARGET OF 2013 CURRICULUM \\ IMPLEMENTATION IN JAYAPURA REGION
}

\author{
Hulman Simanjuntak ${ }^{1}$ dan Amir Imbaruddin ${ }^{2}$ \\ ${ }^{1}$ LPMP Papua \\ e-mail: hulmansimanjuntak22@yahoo.com \\ ${ }^{2}$ Sekolah Tinggi Ilmu Administrasi-Lembaga Administrasi Negara, Makassar \\ e-mail: aimbaruddin@gmail.com
}

\begin{abstract}
Abstrak
Literasi merupakan integrasi keterampilan menyimak, berbicara, menulis, membaca, dan berpikir kritis. Gerakan literasi sekolah terdiri atas tahap pembiasaan, pengembangan, dan pembelajaran. Penelitian ini bertujuan untuk memperoleh gambaran yang jelas tentang implementasi gerakan literasi sekolah di SMA sekolah sasaran pelaksana Kurikulum 2013 tahun pelajaran 2016/2017 se Kabupaten Jayapura. Metode yang digunakan yaitu metode survei dengan deskriptif kuantitatif. Hasil temuan penelitian program membaca 15 menit yang menjadi pogram wajib untuk tahap pembiasaan responden dari peserta didik masih berkategori sedang 2,17, tahap pengembangan berkategori sedang 2,41, dan tahap pembelajaran juga masih berkategori sedang 2,12. Program membaca 15 menit yang menjadi program wajib responden dari pendidik untuk tahap pembiasaan berkategori sedang 2,46, tahap pengembangan berkategori sedang 2,52 , dan tahap pembelajaran juga masih berkategori sedang 2,34. Beberapa sekolah belum menjadwalkan dalam jadwal harian program membaca 15 menit yang menjadi kewajiban sebelum kegiatan pembelajaran dilaksanakan setiap hari. Demikian juga belum memiliki tim gerakan literasi sekolah. Jadi implementasi gerakan literasi sekolah di SMA sekolah sasaran pelaksana Kurikulum 2013 se Kabupaten Jayapura hanya mencapai kategori sedang. Hasilnya dapat dijadikan sebagai masukan kepada LPMP Papua untuk meningkatkan kualitas pelayanan kediklatan demi meningkatkan mutu pendidikan di provinsi Papua.
\end{abstract}

Kata kunci: Gerakan Literasi, Sekolah Menengah Atas, Kurikulum 2013, Pemerintah Kabupaten Jayapura.

\begin{abstract}
Literacy is an integration of listening, speaking, writing, reading, and critical thinking skills. The implementation of the School Literacy Movement consists of the stage of habituation, development, and learning. This study aims to obtain a clear picture of the implementation of School Literacy Movement in Senior High Schools as target school for 2013 Curriculum Academic Year 2016/2017 at Jayapura Region. The method used is survey method with descriptive quantitative and qualitative descriptive. The
\end{abstract}


research findings of the 15-minute program read into the compulsory program for the habituation stage of the respondents of the students are still moderate 2.17 , the development stage is moderate 2.41, and the learning stage is also still moderate 2.12. The 15-minutes Reading Programs which become the compulsory program of respondents from educators for the moderate category of cognition 2.46, the development stage is moderate 2.52, and the learning stage is also still moderate 2.34. Some schools have not scheduled the daily schedule of 15-minute Reading Programs that are required before the learning activities are conducted every day. Some schools do not have a School Literacy Movement Team as well. So the implementation of School Literacy Movement in Senior High Schools as target school for 2013 Curriculum implementation at Jayapura Region reach medium category. The result can be used as input to LPMP Papua to improve training quality services in order to improve the quality of education in Papua Province.

Keywords: Literacy Movement, Senior High School, 2013 Curriculum, Jayapura Region.

\section{PENDAHULUAN}

Pendidikan memegang peran penting dalam proses peningkatan sumber daya manusia. Peningkatan kualitas pendidikan adalah suatu proses yang terintegrasi dalam proses peningkatan sumber daya manusia itu sendiri. Pentingnya proses peningkatan kualitas sumber daya manusia menjadi perhatian Pemerintah dengan terus berupaya membuat program-program untuk mewujudkan pembangunan pendidikan yang lebih berkualitas seperti melalui program perbaikan kurikulum, proses pembelajaran, sistem evaluasi, standar kelulusan, perbaikan sarana dan prasarana pendidikan, pengadaan materi dan pelatihan atau diklat bagi Guru-Guru dan Pengawas Sekolah. Oleh karena itu pelaksanaan dan pengembangan Kurikulum 2013 harus mengacu dan berpedoman pada panduan yang disusun oleh masingmasing direktorat untuk menjamin pencapaian tujuan pendidikan nasional yaitu Peraturan Menteri Pendidikan dan Kebudayaan (Permendikbud) Nomor 20 tahun 2016 Tentang Standar Kelulusan, Permendikbud Nomor 21 Tahun 2016 Tentang Standar Isi, Permendikbud Nomor 22 Tahun 2016 Tentang Standar Proses, Permendikbud Nomor 23 Tahun 2016 Tentang Standar Penilaian, dan Permendikbud Nomor 24 Tahun 2016 Tentang Kompetensi Dasar dan Indikator merupakan acuan utama bagi satuan pendidikan dalam pengembangan Kurikulum 2013.

Literasi adalah kemampuan mengakses, memahami, dan menggunakan sesuatu secara cerdas melalui berbagai aktifitas antara lain: membaca, melihat, menyimak, menulis, dan berbicara (Sutrianto, 2016). Gerakan Literasi Sekolah (GLS) untuk semua jenjang satuan pendidikan merupakan sebuah upaya yang dilakukan secara menyeluruh untuk menjadikan sekolah sebagai organisasi pembelajar yang warganya literat sepanjang hayat melalui pelibatan publik. Pelaksanaan gerakan literasi sekolah di SMA diharapkan menjadi sebuah peningkatan budaya membaca siswa, karena dengan gemar membaca merupakan salah satu modal penting bagi seseorang untuk maju dan tampil ke depan. Oleh karena itu, perpustakaan sebagai sumber belajar mengajar meningkakan kualitas kehidupan pembacanya dan dapat mencerdaskan kehidupan bangsa. Hal ini diperkuat oleh penelitian Zweizig dan Hopkins (2016), menyatakan bahwa "Evaluation findings indicate that Library power has produced school library programs that play an important role insupporting teaching ang learning”, yang intinya bahwa program perpustakaan sekolah memberikan andil yang sangat penting dalam mendukung kegiatan belajar mengajar. 
Ferguson (2001) menyatakan bahwa kompetensi literasi informasi yang terdiri atas literasi dasar, literasi perpustakaan, literasi media, literasi teknologi, dan literasi visual dapat mempengaruhi pelaksanaan literasi sekolah. Informasi pada umumnya banyak didapat melalui kelengkapan fasilitas perpustakaan. Untuk mendukung pelaksanaan gerakan literasi sekolah tersebut, LPMP Papua melaksanakan diklat Instruktur Kabupaten dan Guru Sasaran Implementasi Kurikulum 2013 yang di dalamnya termasuk implementasi gerakan literasi sekolah bagi guru Sekolah Menengah Atas se Provinsi Papua tahun 2016/2017.

Ahmad Mujib (2016) menyatakan bahwa Literasi adalah "kemampuan individu untuk membaca, menulis, berbicara, menghitung, dan memecahkan masalah pada tingkat keahlian yang diperlukan dalam pekerjaan, keluarga, dan masyarakat”. Apabila kita melihat kemampuan anak Indonesia dalam PIRLS (Progress in International Reading Literacy Study) pada tahun 2011 berada pada peringkat 45 dari 46 negara. Kemampuan anak Indonesia dalam PISA (Programme for International Student Assessment ) berada pada peringkat 57 dari 65 negara pada tahun 2009. Pada tahun 2012 peringkat anak Indonesia berada di peringkat 64 dari 65 negara. Dan pada tahun 2015 anak Indonesia berada pada peringkat 64 dari 70 negara. Dan sementara untuk INAP (Indonesia National Assessment Program) nilai kemampuan membaca anak Indonesia 46,83\% berkategori kurang, sehingga dapat disimpulkan bahwa minat membaca anak Indonesia masih rendah.

Hasil PISA (Program for International Student Assesment) tahun 2015 mengungkap bahwa kemampuan siswa anak Indonesia berada pada peringkat ke 62 dari 70 negara yaitu matematika memiliki skor 375, bacaan memiliki skor 396, dan sains memiliki skor 382 . Sementara skor tertinggi dimiliki oleh negara Shanghai (China) dengan matematika memiliki skor 613 , bacaan memiliki skor 570, dan sains memiliki skor 580. Kemampuan siswa anak Indonesia berada pada peringkat 62 dari 70 negara (sumber Kemdikbud OECD), dapat disimpulkan bahwa motivasi dan budaya minat membaca siswa anak Indonesia masih sangat rendah dan memprihatinkan. Guru-guru belum menerapkan membaca buku sebelum mengajar, buku-buku referensi di sekolah masih belum memadai, perpustakaan sekolah belum memadai, dan Guru belum memiliki strategi untuk memotivasi Siswa agar budaya minat membaca tinggi. Pada kegiatan PISA tahun 2015 bahwa anak dari Papua belum pernah diikutkan karena kemampuan mereka masih rendah atau dibawah rata-rata dibanding dengan anak dari Provinsi lain di Indonesia.

Guru Peserta Diklat Kurikulum 2013 yang dilaksanakan oleh LPMP Papua adalah guru dan kepala sekolah berasal dari Kabupaten Jayapura melibatkan guru yang mengajar di kelas X pada lima SMA sebagai sekolah sasaran pelaksana Kurikulum 2013 yaitu SMA Negeri 1 Sentani Jayapura, SMA Negeri 2 Maribu, SMA Adven Doyo Baru Sentani, SMA YPK Sentani, dan SMA YPPK ASISI Sentani dimana masing-masing sekolah mengirimkan sebelas guru mata pelajaran. Saat mengikuti diklat Kurikulum 2013, semua peserta mendapat materi gerakan literasi sekolah, namun ada beberapa peserta diklat yang terlambat mengikuti materi, kurang serius. Peserta diklat yang sudah tergolong umur dalam arti sudah mau pensiun, kurang semangat. Bahkan beberapa orang pendidik hanya orientasi sertifikat diklat untuk dipergunakan pengusulan DUPAK, dan guru belum memahami strategi meningkatkan budaya minat membaca peserta didik.

Tujuan dari Penelitian ini adalah untuk memperoleh gambaran yang jelas mengenai implementasi gerakan literasi sekolah di SMA sekolah sasaran 
pelaksana kurikulum 2013 tahun pelajaran 2016/2017 se-Kabupaten Jayapura.

\section{METODE PENELITIAN}

\section{Jenis Penelitian}

Penelitian ini menggunakan metode survei dengan pendekatan deskriptifkuantitatif untuk $\mathrm{m}$ e $\mathrm{n} \mathrm{d}$ i s k r i p s i k a $\mathrm{n}$ pelaksanaan gerakan literasi sekolah di SMA sekolah sasaran pelaksana Kurikulum 2013 di lingkungan Dinas Pendidikan dan Pengajaran Kabupaten Jayapura yang terdiri atas tiga tahap yaitu tahap pembiasaan, tahap pengembangan, dan tahap pembelajaran.

\section{Unit Analisis}

Unit analisis dalam penelitian ini adalah Pendidik yang mengajar di kelas $\mathrm{X}$ dan Peseta Didik kelas $\mathrm{X}$ dari SMA sekolah sasaran pelaksana Kurikulum 2013 tahun pelajaran 2016/2017 se Kabupaten Jayapura sebanyak 818 orang. Penetapan sampel menggunakan simple random sampling dengan diperoleh sampel sebanyak 181 orang, yang dapat diolah sebanyak 172 orang. data (tabulating). Teknik analisa data dilakukan dengan cara pembuatan tabel distribusi frekuensi yang ditetapkan berdasarkan Skala Likert. Kriteria penskoran implementasi gerakan literasi sekolah berdasarkan skala likert seperti dalam tabel berikut:
Tabel 1

Kriteria Penskoran berdasarkan Skala Likert

\begin{tabular}{|l|c|c|}
\hline Alternatif Jawaban & Bobot & Kriteria \\
\hline $4,01-5,00$ & 5 & Sangat Tinggi \\
\hline $3,01-4,00$ & 4 & Tinggi \\
\hline $2,01-3,00$ & 3 & Sedang \\
\hline $1,01-2,00$ & 2 & Rendah \\
\hline $0,01-1,00$ & 1 & Sangat Rendah \\
\hline
\end{tabular}

\section{HASIL PENELITIAN}

Gambaran umum Pendidik yang mengajar di kelas $\mathrm{X}$ dan Peseta Didik kelas X SMA sekolah sasaran pelaksana Kurikulum 2013 se Kabupaten Jayapura tahun pelajaran 2016/2017 ditampilkan dalam tabel sebagai berikut:

Tabel 2

Profil Pendidik dan Peserta Didik kelas X SMA Sekolah Sasaran Pelaksana Kurikulum 2013

\begin{tabular}{|l|c|c|}
\hline Nama Sekolah & $\begin{array}{c}\text { Jumlah Peserta } \\
\text { Didik kelas X }\end{array}$ & $\begin{array}{c}\text { Jumlah Pendidik } \\
\text { kelas X yang } \\
\text { mengikuti diklat }\end{array}$ \\
\hline SMA N 1 Sentani & 397 & 11 \\
\hline SMA N 2 Maribo Sentani & 88 & 11 \\
\hline SMA YPK Sentani & 61 & 11 \\
\hline SMA YPPK Sentani & 146 & 11 \\
\hline SMA Adven Doyo Sentani & 71 & 11 \\
\hline Jumlah & 763 & 55 \\
\hline
\end{tabular}

Sumber : SMA sekolah sasaran pelaksana Kurikulum 2013

\section{Teknik Pengumpulan Data}

Teknik pengumpulan data dilakukan dengan penyebaran kuesioner yang didukung dengan wawancara, observasi, dan telaah dokumen.

\section{Teknik Pengolahan dan Analisis Data}

Pengolahan data diawali dengan reduksi data, kemudian dilakukan dengan pemeriksaan data dan tabulasi

\section{Kondisi Awal (Input)}

Semua Tenaga Pendidik Mata Pelajaran yang mengajar kelas X SMA Negeri 1 Sentani, SMA Negeri 2 Maribu, SMA ADVEN Doyo Baru, SMA YPPK ASISI Sentani, dan SMA YPK Sentani di Kabupaten Jayapura sebagai sekolah sasaran pelaksana Kurikulum 2013 tahun pelajaran 2016/2017 telah mendapat Diklat Implementasi Kurikulum 2013, 
termasuk di dalamnya implementasi gerakan literasi sekolah di LPMP Papua. Mereka telah mendapat materi gerakan literasi sekolah, yakni bagaimana cara menerapkannya, bagaimana tahapannya, tujuannya, prinsipnya, serta kesiapan dalam melaksanakannya di sekolah. Wiedarti, (2016) menyatakan bahwa "literasi mencakup bagaimana seseorang berkomunikasi dalam masyarakat, praktik dan hubungan sosial yang terkait dengan pengetahuan, dan bahasa. Didukung oleh Permendikbud No. 23 tahun 2015 yaitu langkah awal yang ditempuh untuk mewujudkan gerakan literasi adalah tahap pembiasaan, tahap pengembangan, dan tahap pembelajaran yang dilakukan selama 15 menit dengan cara membaca buku yang disesuaikan dengan konteks atau target sekolah.

\section{Tahap Pembiasaan}

Tahap pembiasaan yaitu membaca dalam hati yang bertujuan untuk meningkatkan rasa cinta membaca di luar jam pelajaran, meningkatkan kemampuan memahami bacaan, meningkatkan rasa percaya diri sebagai pembaca yang baik dan menumbuhkembangkan penggunaan berbagai sumber bacaan (Permendikbud, No.23 Tahun 2015). Tahap pembiasaan gerakan literasi sekolah dari responden ditunjukkan dalam tabel berikut:

Tabel 3

Keseluruhan Jawaban Responden Tahap Pembiasaan

\begin{tabular}{|c|l|c|c|c|c|}
\hline \multirow{2}{*}{ No } & \multirow{2}{*}{ Nama Sekolah } & \multicolumn{4}{|c|}{ Tahap Pembiasaan } \\
\cline { 3 - 6 } & & Psrt Didik & Kategori & Pendidik & Kategori \\
\hline 1 & SMA N 1 Sentani & 2,13 & Sedang & 2,73 & Sedang \\
\hline 2 & SMA N 2 Maribu & 1,88 & Rendah & 2,39 & Sedang \\
\hline 3 & SMA Advent Doyo Baru & 2,49 & Sedang & 2,62 & Sedang \\
\hline 4 & SMA YPPK ASISI & 2,39 & Sedang & 2,43 & Sedang \\
\hline 5 & SMA YPK Sentani & 1,99 & Rendah & 2,15 & Sedang \\
\hline \multicolumn{2}{|c|}{ Skor rata-rata } & 2,17 & Sedang & 2,46 & Sedang \\
\hline
\end{tabular}

secara lisan maupun tulisan yang belum dinilai akademiknya. Tahap pengembangan gerakan literasi sekolah dari Responden ditunjukkan dalam tabel berikut:

Sumber: Data Olahan Angket Penelitian 
Tabel 4

Keseluruhan Jawaban Responden Tahap Pengembangan

\begin{tabular}{|ll|c|c|c|c|}
\hline \multirow{2}{*}{ No Nama Sekolah } & \multicolumn{4}{|c|}{ Tahap Pengembangan } \\
\cline { 3 - 6 } & & Psrta Didik & Kategori & Pendidik & Kategori \\
\hline 1 & SMA N. 1 Sentani & 2,43 & Sedang & 2,05 & Sedang \\
\hline 2 & SMA N 2 Maribu & 2,28 & Sedang & 2,62 & Sedang \\
\hline 3 & SMA Advent Doyo Baru & 2,56 & Sedang & 2,72 & Sedang \\
\hline 4 & SMA YPPK ASISI & 2,59 & Sedang & 2,75 & Sedang \\
\hline 5 & SMA YPK Sentani & 2,23 & Sedang & 2,47 & Sedang \\
\hline & Skor rata-rata & 2,41 & Sedang & 2,52 & Sedang \\
\hline
\end{tabular}

Data Olahan Angket Penelitian

Tabel 4 di atas menunjukkan bahwa responden dari Peserta Didik yang memiliki rata-rata skor terendah yaitu 2,23 adalah SMA YPK Sentani dan masuk kategori sedang, rata-rata skor tertinggi yaitu 2,59 adalah SMA YPPK ASISI masih masuk kategori sedang. Responden dari Pendidik yang memiliki rata-rata skor terendah 2,05 adalah SMA Negeri 1 Sentani masih masuk kategori sedang, dan rata-rata skor tertinggi 2,75 adalah SMA YPPK ASISI juga masih masuk kategori sedang.

Hasil wawancara dari Peserta Didik menyatakan bahwa Mereka (Peserta Didik) belum memiliki buku mata pelajaran yang berbasis kurikulum 2013 termasuk buku revisi 2016, sementara buku-buku di perpustakaan tidak mencukupi sesuai dengan jumlah peserta didik dan belum memiliki area baca yang nyaman dengan koleksi buku non pelajaran untuk berbagai kegiatan literasi. Sedangkan Pendidik menyatakan bahwa karena Peserta Didik banyak tidak membawa buku non mata pelajaran, bahkan ada yang tidak masuk sekolah pada waktu membaca 15 menit, sehingga Peserta Didik tidak dapat menanggapi dan mengomentari buku yang telah dibaca baik secara lisan maupun tulis.

\section{Tahap Pembelajaran}

Tahap Pembelajaran adalah lanjutan dari tahap pembiasaan dan pengembangan untuk $\mathrm{m}$ e $\mathrm{n}$ g e $\mathrm{m} \mathrm{b}$ a $\mathrm{n} \mathrm{g} \mathrm{k} \mathrm{a} \mathrm{n}$ kemampuan memahami teks mata pelajaran dan mengaitkan dengan pengalaman pribadi sehingga terbentuk pribadi pembelajar sepanjang hayat, $\mathrm{m}$ e $\mathrm{n}$ g e m b a n g k a $\mathrm{n}$ kemampuan berpikir kritis, mengolah dan mengelola kemampuan komunikasi secara kreatif. Tahap pembelajaran gerakan literasi sekolah dari Responden ditunjukkan dalam tabel berikut:

Tabel 5

Responden Tahap Pembelajaran

\begin{tabular}{|c|c|c|c|c|c|}
\hline No & Nama Sekolah & \multicolumn{4}{|c|}{ ahap Pembelajaran } \\
\hline & & Psrta Didik & Kategori & Pendidik & Kategori \\
\hline 1 & SMA N. 1 Sentani & 1,83 & Rendah & 2,30 & Sedang \\
\hline 2 & SMA N 2 Maribu & 2,04 & Sedang & 2,30 & Sedang \\
\hline 3 & SMA Advent Doyo Baru & 2,26 & Sedang & 2,38 & Sedang \\
\hline 4 & SMA YPPK ASISI & 2,33 & Sedang & 2,46 & Sedang \\
\hline 5 & SMA YPK Sentani & 2,16 & Sedang & 2,27 & Sedang \\
\hline & r rata-rata & 2,12 & Sedang & 2,34 & Sedang \\
\hline
\end{tabular}

Sumber: Data Olahan Angket Penelitian

Tabel 5 di atas menunjukkan bahwa Responden dari Peserta Didik yang memiliki rata-rata skor terendah 1,83 adalah SMA Negeri 1 Sentani yang msuk kategori rendah, memiliki rata-rata skor tertinggi 2,33 adalah SMA YPPK ASISI yang masuk kategori sedang. Responden dari Pendidik memiliki rata-rata skor terendah 2,27 adalah SMA YPK Sentani yang masuk kategori sedang, skor tertinggi 2,46 adalah SMA YPPK ASISI juga masuk kategori sedang.

Hasil wawancara dari Peserta Didik menyatakan bahwa Mereka (Peserta Didik) belum memiliki buku mata pelajaran yang berbasis Kurikulum 2013 termasuk buku revisi 2016, sementara buku-buku di perpustakaan tidak mencukupi sesuai dengan jumlah peserta didik. Demikian pula Pendidik menyatakan bahwa Peserta Didik belum memiliki buku berbasis Kurikulum 2013 
revisi 2016. Namun dalam proses pembelajaran, Pendidik berusaha mencari sumber dari buku yang lain dan dari buku kurikulum 2013 sebelumnya. Kalaupun mereka memiliki buku, kebanyakan hasil print out dari internet.

\section{PEMBAHASAN}

Agar sekolah mampu menjadi garis depan dalam pengembangan literasi, Beers (2009) menyampaikan strategi menciptakan budaya literasi yang positif di sekolah yaitu mengkondisikan lingkungan fisik ramah literasi, mengupayakan lingkungan sosial dan afektif sebagai model komunikasi dan interaksi yang literat, mengupayakan sekolah sebagai lingkungan akademik yang literat. Pelaksanaan gerakan literasi sekolah memiliki tiga tahapan yaitu tahap pembiasaan, tahap pengembangan, dan tahap pembelajaran (Permendikbud, No.23/2015).

Pentingnya tahap pembiasaan agar Peserta Didik mulai merasa cinta, termotivasi dan rasa percaya diri dalam membaca buku yang dibacanya. Tahap pembiasaan membaca 15 menit yang menjadi program wajib di SMA sekolah sasaran pelaksana Kurikulum 2013 Kabupaten Jayapura masih berkualitas sedang. Tahap pembiasaan yang perlu mendapat perhatian dan peningkatan oleh satuan pendidikan karena masih ada yang berkualitas rendah yaitu indikator nomor 5 Guru memfasilitasi peserta didik memanfaatkan perpustakaan, sudut baca di tiap kelas, dan area baca yang nyaman dengan koleksi buku non pelajaran; indikator nomor 7 Guru menggunakan bahan karya teks yang terpampang di tiap kelas; dan indikator nomor 8 Guru memfasilitasi Peserta Didik menggunakan kebun sekolah, kantin, dan UKS menjadi lingkungan yang bersih, sehat dan kaya teks. Indikator dalam tahap pembiasaan ini merupakan ciri khas literasi sekolah seperti setiap kelas memiliki sudut baca, hasil karya teks membaca Peserta Didik terpampang di tiap kelas, di kantin, di
UKS, di taman, di kebun sekolah, dan di pekarangan sekolah sehingga lingkungan sekolah menjadi bersih, sehat, dan kaya teks. Oleh karena itu, tata ruang perpustakaan sekolah perlu memperhatikan prinsip-prinsip arsitektur, azas tata ruang, tata letak, desain, dan kebutuhan ruangan agar nyaman, aman, dan selamat dalam pengggunaannya (Lasa, 2007).

Pentingnya tahap pengembangan dilaksanakan untuk mengasah kemampuan Peserta Didik dalam berpikir kritis, analitis, kreatif, inovatif, dan menanggapi buku yang dibacanya secara lisan dan tulis. Tahap pengembangan yang menuntut anak dapat paham dan mengomentari buku yang dibaca masih berkualitas sedang. Tahap pengembangan yang perlu mendapat perhatian oleh satuan pendidikan karena masih berkategori rendah yaitu indikator nomor 14 Guru memfasilitasi peserta didik memanfaatkan perpustakaan, sudut baca di tiap kelas, dan area baca yang nyaman dengan koleksi buku non pelajaran dimanfaatkan untuk berbagai kegiatan literasi. Indikator tersebut dalam tahap pengembangan perlu lebih diperhatikan agar Peserta Didik terbiasa menanggapi, mengomentari, mengkritisi buku yang telah dibaca.

Pentingnya tahap pembelajaran karena dituntut dari Peserta Didik tagihan yang sifatnya akademis terkait dengan mata pelajaran untuk penilaian. Dalam tahap pembelajaran ini, berbagai jenis kegiatan dapat dilakukan, antara lain 15 menit membaca setiap hari sebelum pelajaran, apakah dengan membaca nyaring, membaca dalam hati, membaca bersama, atau membaca terpadu diikuti dengan tangihan akademik. Tahap pembelajaran yang menjadi tahap ketiga dalam implementasi gerakan literasi sekolah masih berkualitas sedang karena Peserta Didik secara umum belum memiliki buku mata pelajaran berbasis Krikulum 2013 revisi 216. Khususnya untuk SMA 
YPK Sentani bahwa tahap pembelajaran yang perlu mendapat perhatian dan peningkatan karena masih ada yang berkualitas rendah yaitu indikator nomor 18, Guru memfasilitasi kegiatan membaca pada tempatnya selain lima belas menit sebelum pembelajaran sudah membudaya dan menjadi kebutuhan Warga Sekolah (tampak dilakukan oleh semua Warga Sekolah); indikator nomor 21, Guru memfasilitasi berbagai kegiatan tindak lanjut dalam bentuk menghasilkan respon secara lisan maupun tulisan (tagihan akademik); dan indikator nomor 22, Guru memfasilitasi Peserta Didik membuat portofolio yang berisi kumpulan jurnal respon membaca minimal 12 (dua belas) buku nonpelajaran. Tahap pembelajaran ini sangat perlu dilatihkan kepada Peserta Didik secara terus menerus agar dapat menumbuhkan budaya minat membaca sehingga dapat menghasilkan respon secara lisan dan tulis dari buku mata pelajaran yang mereka pelajari sebagai tagihan akademik. Anderson \& Krathwol (2016) menyatakan bahwa tujuan literasi tahap pembelajaran yaitu, mengolah dan mengelola kemampuan komunikasi secara kreatif (verbal, tulisan, visual, digital) melalui kegiatan menanggapi buku bacaan dan buku pelajaran.

Pelaksanaan gerakan literasi sekolah di SMA Negeri 1 Sentani telah dilakukan terjadwal program membaca 15 menit di awal pelajaran, dievaluasi setiap minggu, dan telah memiliki tim gerakan literasi sekolah. Peserta Didik sudah 66,43\% memiliki jurnal membaca harian. SMA YPPK ASISI Sentani, program membaca 15 menit sebelum pelajaran sudah terjadwal, tapi belum memiliki tim gerakan literasi sekolah. Peserta Didik baru 51,25\% telah memiliki jurnal membaca harian dan hanya satu kali dalam satu bulan dilaksanakan evalasi mingguan. SMA ADVENT Doyo Baru program membaca 15 menit sebelum pelajaran sudah terjadwal, tapi belum memiliki tim gerakan literasi sekolah. Peserta Didik baru 50,86\% telah memiliki jurnal membaca harian dan hanya satu kali dalam satu bulan dilaksanakan evalasi mingguan. SMA Negeri 2 Maribu program membaca 15 menit di awal pelajaran belum terjadwal, dan belum memiliki tim gerakan literasi sekolah, namun Pendidik telah melaksanakannya di kelas masing-masing. Peserta Didik baru $42,42 \%$ yang telah memiliki jurnal membaca harian dan hanya dua kali dalam satu semester dilaksanakan evaluasi mingguan. SMA YPK Sentani program membaca 15 menit di awal pelajaran belum terjadwal, dan belum memiliki tim gerakan literasi sekolah, namun Pendidik telah melaksanakannya di kelas masing-masing. Peserta Didik baru 41,65\% yang telah memiliki jurnal membaca harian dan hanya dua kali dalam satu semester dilaksanakan evaluasi mingguan.

Kepala Sekolah, Pendidik, dan Tenaga Kependidikan belum bertindak sebagai model dalam gerakan literasi sekolah, walaupun program kebijakan gerakan literasi sekolah telah disosialisasikan dan disampaikan oleh kepala Sekolah maupun Guru. Melalui proram literasi sekolah diharapkan warga sekolah melaksanakan secara konsisten dengan melakukan evaluasi secara terus menerus, agar tujuan peningkatan kemampuan literasi yang diharapkan Pemerintah dapat dicapai. Skor literasi dalam penilaian secara internasional seperti PISA (Program for International Study Assessment), PIRLS (Progress in International Reading Literacy Study), dan INAP (Indonesia National Assessment Program) dimasa yang akan datang mengalami peningkatan. Oleh sebab itu, peran pendidik, buku pelajaran, non pelajaran, buku teks, buku panduan, buku pengayaan, koran, majalah, media, kebun sekolah, taman, lorong-lorong, kantin, UKS yang layak sangat penting untuk menunjang dan mendukung program membaca 15 menit sebelum pembelajaran dimulai. Peran dan keberadaan perpustakaan sekolah yang baik dan lengkap dapat 
meningkatkan kemampuan literasi Peserta Didik dalam proses belajar mengajar, melakukan penelitian, mengembangkan minat baca, membiasakan Peserta Didik mencari informasi sendiri secara manual maupun melalui komputer, memperluas kesempatan belajar melalui bacaan ringan seperti surat kabar, majalah populer maupun buku-buku fiksi (Khairani, 2001).

Implementasi gerakan literasi sekolah yang dicanangkan bagi sekolah sasaran pelaksana Kurikulum 2013 di SMA se Kabupaten Jayapura tahun pelajaran 2016/2017 belum dilaksanakan sepenuhnya dengan baik oleh sekolah. Dari ketiga tahapan yaitu tahap pembiasaan, tahap pengembangan, dan tahap pembelajaran belum ada SMA yang berkualitas baik atau sangat baik. Semuanya masih berada pada kualitas sedang.

\section{KESIMPULAN DAN SARAN}

Implementasi gerakan literasi sekolah di SMA sekolah sasaran pelaksana Kurikulum 2013 tahun pelajaran 2016/2017 se Kabupaten Jayapura berada pada kategori sedang. Hasil respon Peserta Didik tahap pembiasaan berkategori sedang, tahap pengembangan berkategori sedang, dan tahap pembelajaran berkategori sedang. Responden Pendidik tahap pembiasaan berkategori sedang, tahap pengembangan berkategori sedang, dan tahap pembelajaran berkategori sedang. Hasil wawancara dengan Pendidik menyatakan bahwa Peserta Didik banyak tidak membawa buku teks, novel, koran, bahkan ada yang tidak masuk sekolah pada waktu membaca 15 menit. Hasil wawancara dengan Peserta Didik menyatakan bahwa sebagian besar Peserta Didik belum memiliki buku mata pelajaran berbasis Kurikulum 2013 revisi 2016. Untuk meningkatkan pelaksanaan gerakan literasi sekolah maka perlu: Guru SMA selaku Peserta Diklat untuk mengikuti kegiatan dengan baik dan dapat bekerja sama antara sesama Peserta, Panitia, Widyaiswara; perlu mengimplementasikan gerakan literasi sekolah di sekolahnya setelah selesai diklat atau sekembalinya ke tempat tugasnya masing-masing; perlu menjadwalkan pelaksanaan literasi 15 menit sebelum jam pelajaran; dan perlu membentuk tim literasi sekolah untuk mengatur pelaksanaannya.

\section{REFERENSI}

Beers, 2009. A Principal's Guide to Literacy Instruction. Ohio: Pearson Merrill Prentice Hall, Upper Saddle River, New Jersey Columbus.

Ferguson, C. 2015. Information Literacy. A Primer for Teachers, Librarians, and other Informed People. http:// www.bibliotech.us/pdfs/ InoLit.pdf. Diakses pada 14 Oktober 2017.

Khairani, M. 2001. Pengembangan Minat Baca. Makalah disajikan dalam pelatihan pengelolaan perpustakaan.

Krathwol, A. 2016. Tujuan Kegiatan Literasi di Tahap Pembelajaran. Panduan Gerakan Literasi Sekolah Menengah Atas. Jakarta: Direktorat Jenderal Pendidikan Dasar dan Menengah Kementerian Pendidikan dan Kebudayaan.

Lasa, HS. 2007. Manajemen Perpustakaan Sekolah. Yogyakarta: Pinus Book Publisher.

Mujib, Ahmad. 2016. Apa sih literasi itu? h t t p : / / wiki pendidikan . blogspot.co.id pengertian-defenisimakna-literasi.html. Diakses tanggal 19 September 2017.

PISA. 2015. Result in Focus. 2016, https:/ /www.oecd.org/pisa/keyfindings/ pisa-2012-results-overview.pdf. Diakses pada 13 Oktober 2017. 
Sutrianto, 2016. Panduan Literasi Sekolah di Sekolah Menengah Atas. Jakarta: Direktorat Jenderal Pendidikan Dasar dan Menengah Kementerian Pendidikan dan Kebudayaan.

Wiedarti, P. 2016. Desain Induk Gerakan Literasi Sekolah. Jakarta: Direktorat Jenderal Pendidikan Dasar dan Menengah Kementerian Pendidikan dan Kebudayaan.

Zweizig dan Hopkins. 2016. National Library Power Program. http:// www.cde.ca.gov/ci/cr/lb/ natllibrarypwrprg.asp. Diakses pada 13 Oktober 2017. 